\title{
Straightening regulation optimization on the residual stress induced by the compound roll straightening in the heavy rail
}

\author{
Hua Song ${ }^{\mathrm{a}, *}$, Peilong Wang ${ }^{\mathrm{a}}$, Lihua Fu ${ }^{\mathrm{a}}$, Ming Chen ${ }^{\mathrm{a}}$, Zhongqiang Wang ${ }^{\mathrm{b}}$ and Huiyuan Sun $^{\mathrm{b}}$ \\ a School of Mechanical Engineering and Automation, Liaoning University of Science and Technology, Anshan, \\ 114051, Liaoning, China \\ ${ }^{\mathrm{b}}$ Anshan Iron \& Steel Co. Ltd., Anshan 14021, Liaoning, China
}

Received 6 February 2010

Revised 8 July 2010

\begin{abstract}
Residual stress is very important to the straightened quality of rail, this paper adopts explicit dynamics FEM to study on residual stress. We established compound roller model and calculated the residual value of heavy rail through 9 roller horizontal straightening and 8 roller vertical straightening. The reductions of straightening rollers are taken as the main effective factor to the residual stress in the straightening process. We adopt orthogonal calculation method to obtain the main effective factor to residual stress. On the base of assurance of the straightness, we obtained the optimal regulation in which the residual stress is the smallest, so the paper makes the important theoretical and actual sense to formulate the rational straightening regulation and improve the straightening quality of rail.
\end{abstract}

Keywords: Heavy rail, compound straightening, numerical simulation, residual stress

\section{Introduction}

Heavy rail is an important part of railway transportation, it bears heavy impact load over a long period of time. The wearability and antifatigue intensity of rail are directly affected by the interior residual stress value and distributive condition when the heavy rail is working [1-3], the interior residual stress value and distributive condition also decides the finishing rate and the quality of rail. The final deformation process of rail production is straightening, which has direct effect on the value and distribution of residual stress [4-6]. In the assurance of straightened rail quality, it should be studied.

The last process of rail production is straightening, which finally determines the residual stress and straightness. Reference [7] focused on the numerical simulation of nine roller H-straightening, on the occasion that only one of the roller reductions is changed, the other three rollers aren't changed, then reference [7] elaborated the impact on rail residual stress caused by the reduction. Reference [8] selected the orthogonal experimental method of four factors and three levels to study the impact on the straightness and the residual stress of straightened rail caused by reduction and original curvature. Reference [9] carried out the four factors and three levels orthogonal experiment to the horizontal roller, and also studied the impact on the straightness and the residual stress of straightened rail caused by the straightening roller reduction.

The compound roll straightening machine of Angang steel company limited is studied in the paper, and the explicit dynamics software ANSYS/LS-DYNA [15] is adopted to simulate the straightening process in which the $60 \mathrm{~kg} / \mathrm{m}$

\footnotetext{
*Corresponding author. E-mail: songhua88@126.com.
} 


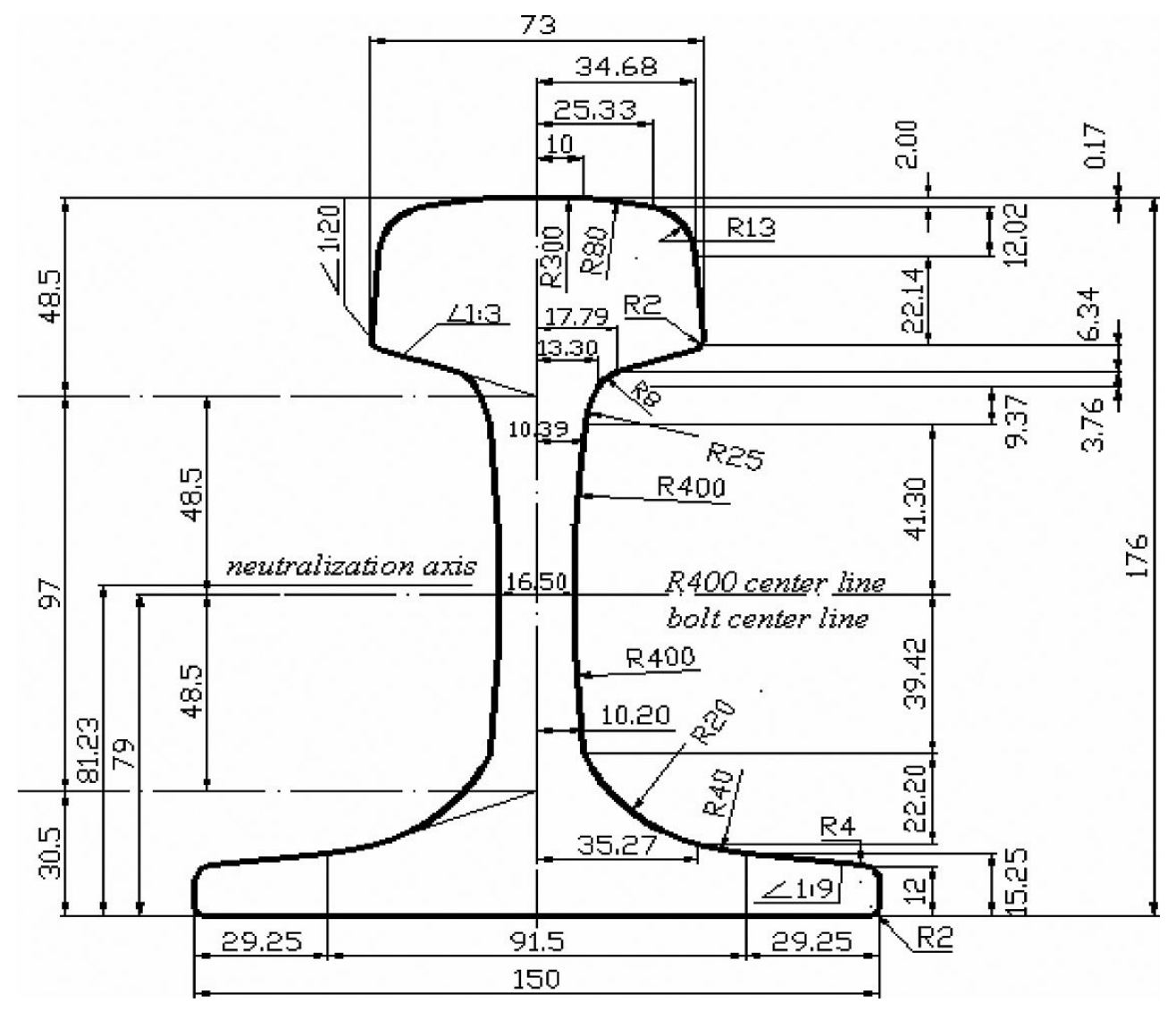

Fig. 1. Section size of $60 \mathrm{Kg} / \mathrm{m}$ heavy rail.

heavy rail has $63 \mathrm{~m}$ deformation curvature radium, we obtained the residual stress and its distribution in straightened rail. We adopted the orthogonal calculation method to obtain the main effective factors for residual stress. In the assurance of meeting the straightness, it obtained the regulation in which the residual stress is the smallest, so it makes the important theoretical and actual sense to formulate the rational straightening process and improves the straightening quality of rail.

\section{FEM model foundation of rail straightening}

Through the data of Angang steel company limited, the maximum value of heavy rail original deformation curvature radius is $63 \mathrm{~m}$. Therefore, we study the $63 \mathrm{~m}$ original deformation curvature radius of $60 \mathrm{~kg} / \mathrm{m}$. The rail section size shows in Fig. 1.

In the paper, the compound roll straightening machine is composed of the 9 roller H-straightener and the 8 roller V-straightener. The straightening process of heavy rail consists of two typical steps, H-straightening step and V-straightening step. The layout of rail compound straightener shows in Fig. 2. In the process of 9 roller $\mathrm{H}$-straightening, the rail generates 7 elastic-plastic bending deformation. The 1\#, 2\#, 3\# rollers deformed the A elastic-plastic bending zone, the 2\#, 3\#, 4\# straightening rollers deformed the B elastic-plastic bending zone, and so on, the 7 horizontal straightening deforming zones formed. The 10\#, 11\#, 12\# straightening rollers deformed the $\mathrm{H}$ elastic-plastic bending zone, the 11\#, 12\#, 13\# straightening rollers deformed the I elastic-plastic bending zone, and so on, the 6 vertical straightening deforming zones formed. Basic parameters of heavy rail compound roller straightener show in Table 1. 
Table 1

Basic parameters of heavy rail compound roller straightener

\begin{tabular}{lccccc}
\hline straightener & $\begin{array}{c}\text { roller diameter } \\
(\mathrm{mm})\end{array}$ & $\begin{array}{c}\text { roller pitch } \\
(\mathrm{mm})\end{array}$ & $\begin{array}{c}\text { roller } \\
\text { number }\end{array}$ & $\begin{array}{c}\text { roller length } \\
(\mathrm{mm})\end{array}$ & $\begin{array}{c}\text { straightening speed } \\
(\mathrm{mm} / \mathrm{s})\end{array}$ \\
\hline 9-roller H-straightener & 1200 & 1600 & $8+1$ & 200 & 1800 \\
8-roller V-straightener & $750-800$ & 1300 & $7+1$ & 153 & 1800 \\
\hline
\end{tabular}

Table 2

The material performance parameters

\begin{tabular}{cccccc}
\hline $\begin{array}{c}\text { material } \\
\text { parameter }\end{array}$ & $\begin{array}{c}\text { density } \\
\left(\mathrm{kg} / \mathrm{mm}^{3}\right)\end{array}$ & $\begin{array}{c}\text { elastic modulus } \\
(\mathrm{MPa})\end{array}$ & poisson ratio & $\begin{array}{c}\text { yield limited stress } \\
(\mathrm{MPa})\end{array}$ & $\begin{array}{c}\text { tangent modulus } \\
(\mathrm{MPa})\end{array}$ \\
\hline rail & $7.83 \mathrm{e}-6$ & $2.1 \mathrm{e} 5$ & 0.3 & 525 & $1.18 \mathrm{e} 4$ \\
straightening roller & $7.83 \mathrm{e}-6$ & $3.0 \mathrm{e} 5$ & 0.3 & & \\
\hline
\end{tabular}

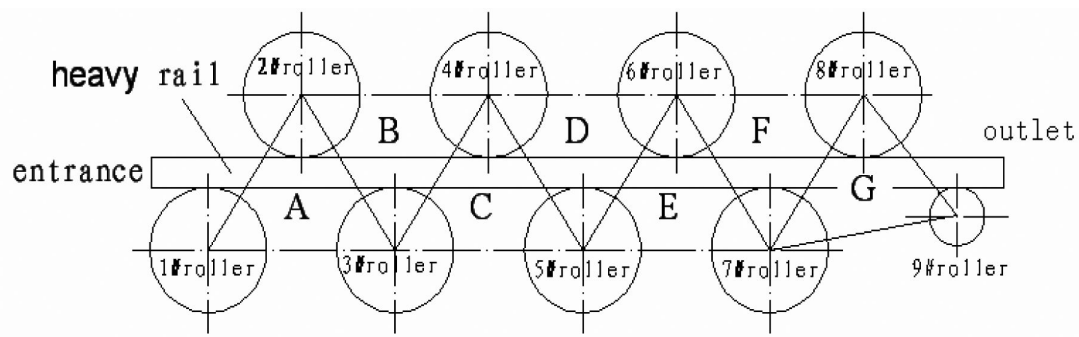

(a) The roller layout of 9-rollers H-straightener.

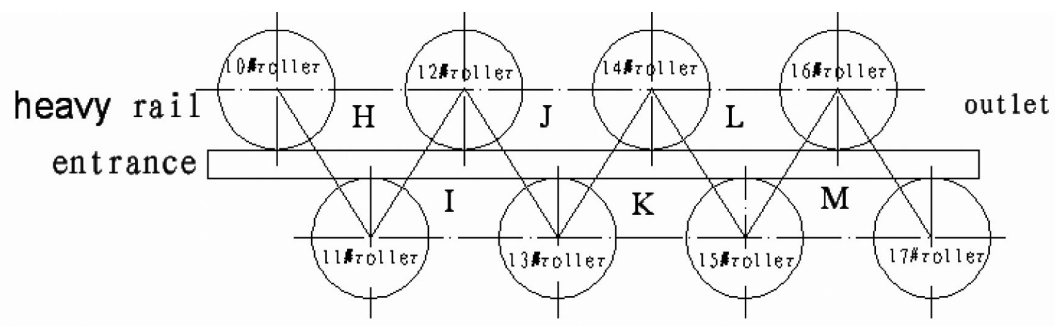

(b) The roller layout of 8-rollers V-straightener

Fig. 2. The layout of rail compound straightener.

Taking consideration of the pitch of straightening roller and the straightening blind area at end of rail, the length of rail is given as $3000 \mathrm{~mm}$ when setting up the FEM model.

The 8 nodes three-dimension solid element SOLID164 is applied to the rail and straightening roller in the simulation process. The rail is defined as deforming body, the double linear reinforce model is applied to it. The straightening roller is simplified to rigid roller, and the rigid material parameters are applied to it. The straightening process is carried out at ordinary temperatures and the material parameters are shown in Table 2.

The whole model is meshed into 198944 elements, 250451 nodes. The model of rail is meshed into 187200 elements, 224147 nodes. The FEM model of rail is shown in Fig. 3.

As the bending deformation of heavy rail mainly happens in the longitudinal direction in the horizontal straightening, the final residual stress is finally formed at the longitudinal direction, so this paper is carried out mainly on the longitudinal residual stress. The longitudinal stress distribution during $\mathrm{H}$-straightening and V-straightening are shown in Figs 4 and 5 respectively.

For further indicating the variety rule of rail inner stress in the compound straightening process, now it studies on the stress value and distribution condition of 36 nodes on the section's symmetry line which is at a distance $1760 \mathrm{~mm}$ from the entrance section of heavy rail. Figure 6 shows the stress change condition of the nodes on the section's symmetry line in every distortion area during the $\mathrm{H}$-straightening process.

The H-straightening of heavy rail finished after seven alternate variational anti-bend distortion, the longitudinal residual stress of section symmetry line after H-straightening shows in Fig. 7. It can be known from Fig. 7, the 


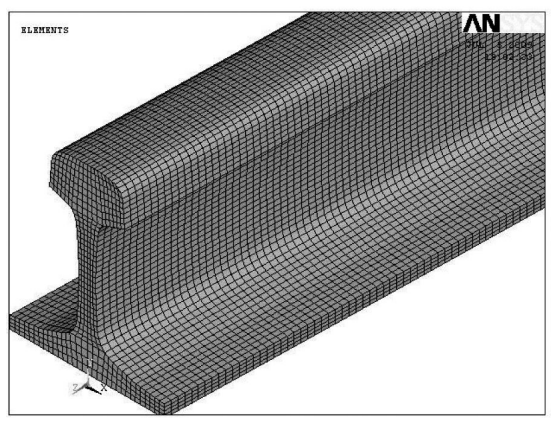

(a) rail model

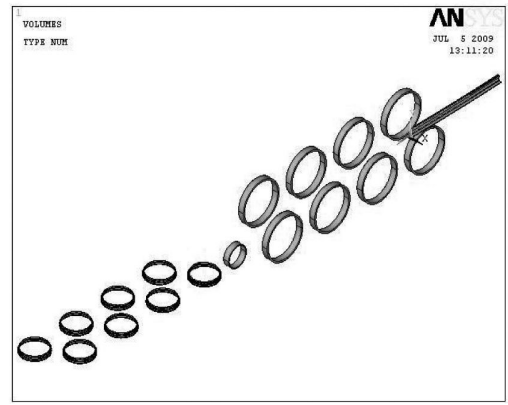

(b) rail compound straightening model

Fig. 3. The rail compound straightening FEM model.

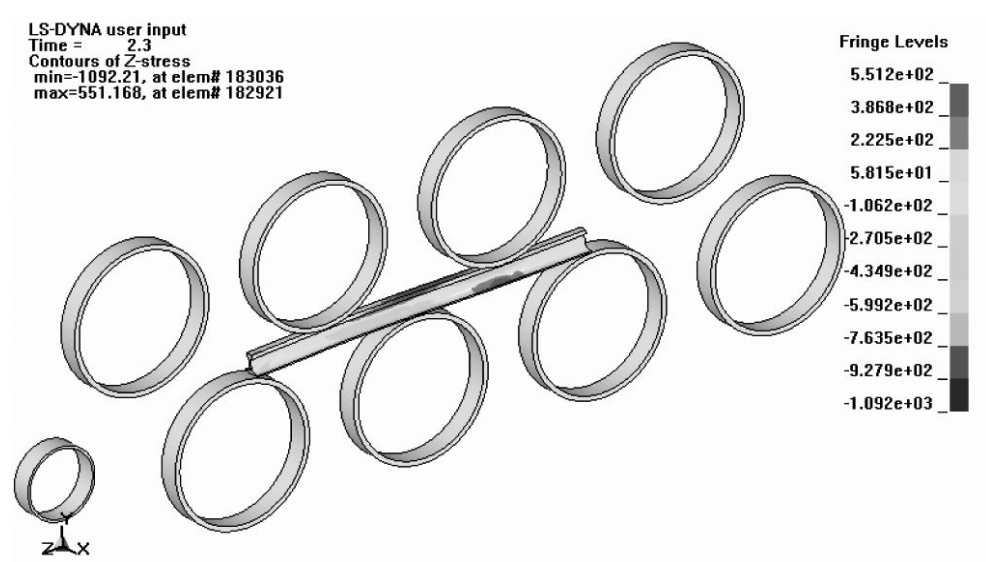

Fig. 4. Longitudinal stress during H-straightening.

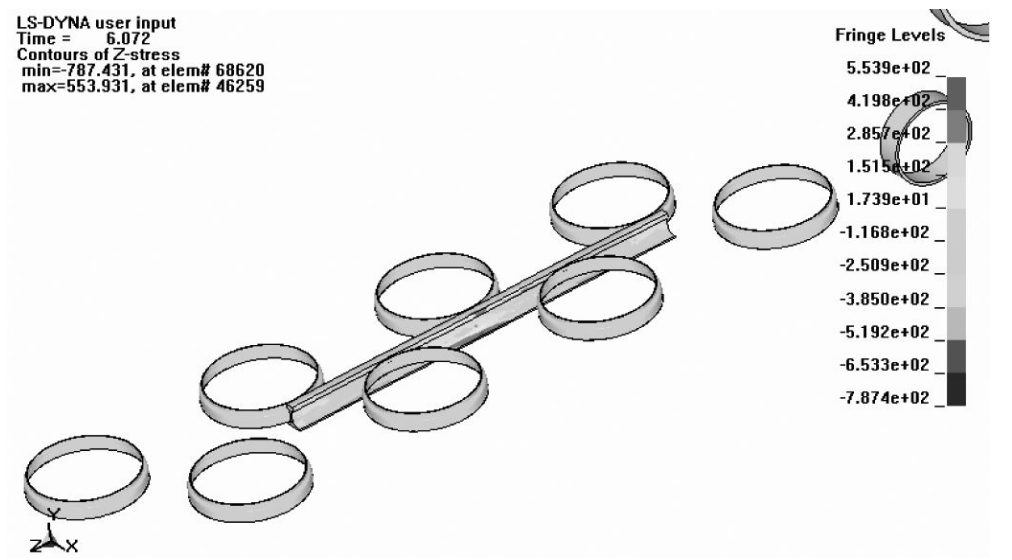

Fig. 5. Longitudinal stress during V-straightening.

longitudinal residual stress after H-straightening on the section's symmetry line is in multi-S shape, the top of rail head, the middle of rail waist, the underside of rail waist and rail bottom is residual tensile stress, the middle of rail head, the underside of rail head and the top of rail waist is residual compressive stress. The results are approximately in accordance with the reference [16].

The stress distribution of the nodes on the section's symmetry line in every deformation area during the V- 


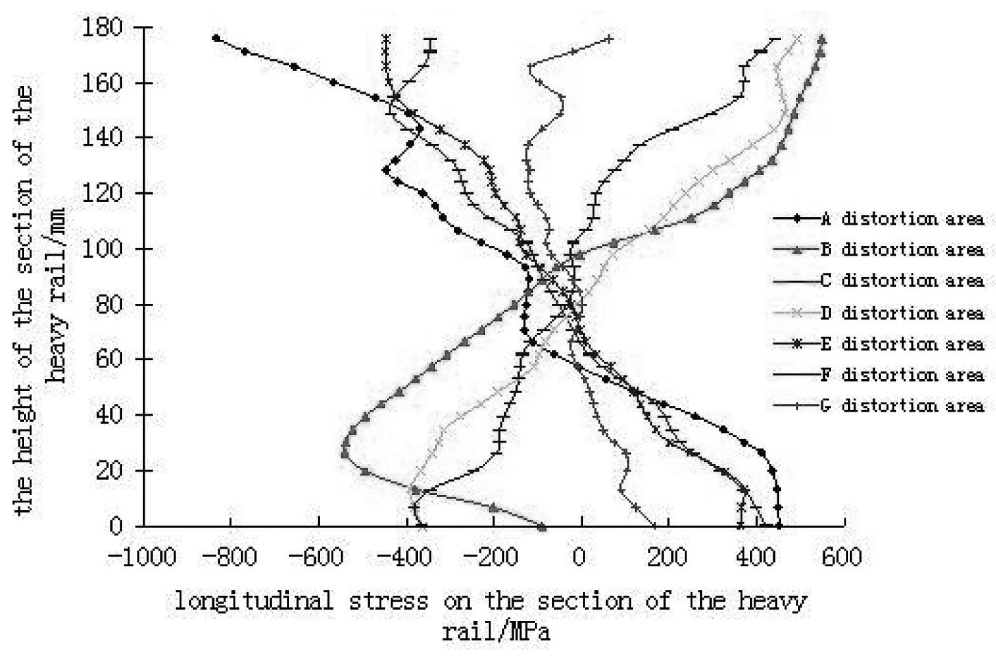

Fig. 6. The stress changing of rail section's symmetry line during H-straightening.

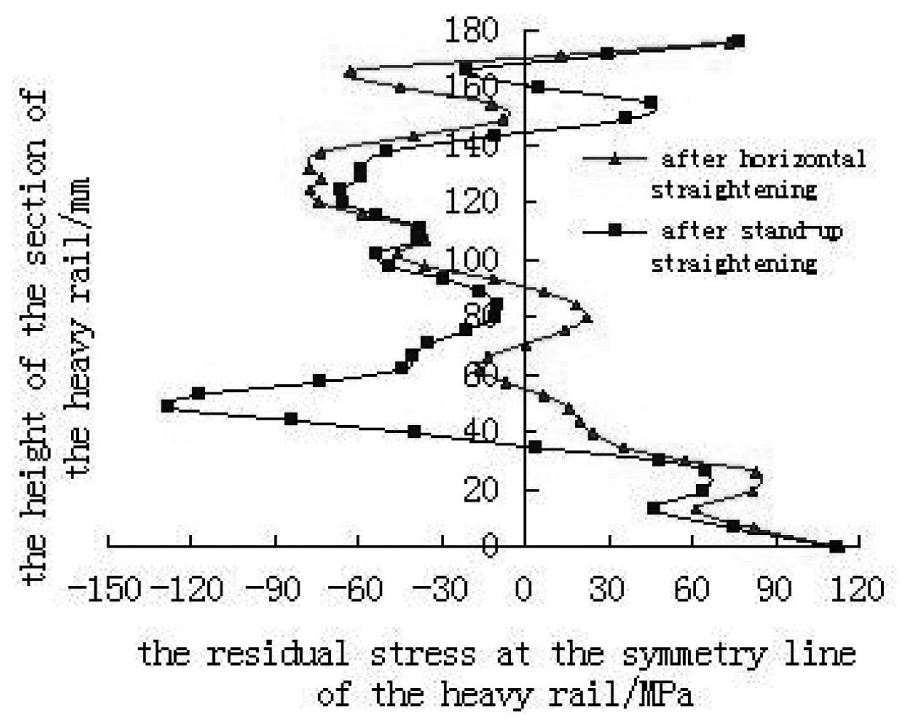

Fig. 7. The residual stress distribution at the rail section's symmetry line.

straightening process shows in Fig. 8. It can be known from Fig. 8, during the V-straightening process, the stress's variety rule of rail section left side in the section's symmetry line is: the compression stress and tensile stress changes alternatively, the stress's variety rule of rail section right side in the section's symmetry line is: the tensile stress and compression stress changes alternatively.

The compound straightening of heavy rail finished after six alternate variational anti-bend distortion, after compound straightening, the longitudinal residual stress of section symmetry line after H-straightening shows in Fig. 7. It is known from Fig. 7, after compound straightening, the distribution of longitudinal residual stress on the section's symmetry line is still in multi-S shape, the top and downside of rail head, rail bottom is residual tensile stress, the middle of rail head and rail waist is residual compressive stress, this stress distribution state is in accordance with the Reference [10] at the top of rail head and rail bottom, the distribution of residual stress in other part is different.

After V-straightening, the distribution of longitudinal residual stress on the section's symmetry line is still in multi-S shape, it is shown in Fig. 8. As to the H-straightening, the rail head is transformed from compression stress condition to tensile stress condition and the residual stress of rail waist is transformed from tensile stress condition 
Table 3

The rail bottom residual stress (unit:MPa)

\begin{tabular}{lcc}
\hline straightening process & H-straightened & V-straightened \\
\hline maximum residual stress & 289.6 & 190.6 \\
average residual stress & 69.5 & 81.1 \\
\hline
\end{tabular}

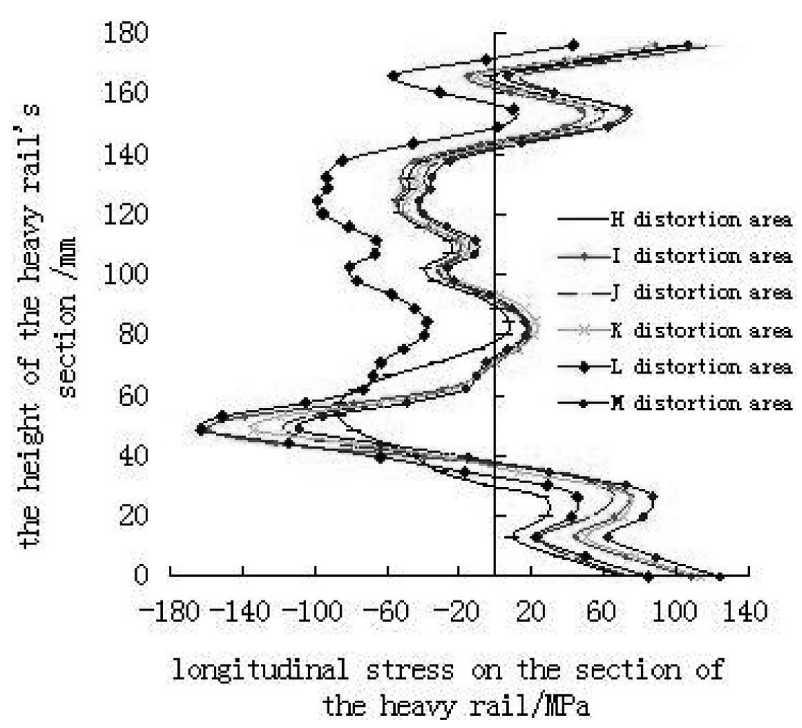

Fig. 8. The residual stress changing of rail section's symmetry line when V-straightening.

to compression stress condition. The position of maximum residual tensile stress of rail is also rail bottom, but the position of maximum residual compression stress is transformed from the top of rail waist to the bottom, and the value is reduced by 51.1 MPa. The increment value of residual tensile stress on the top surface of the rail head is 3.6 $\mathrm{MPa}$, and the residual tensile stress of the rail bottom surface only reduced by $1.0 \mathrm{MPa}$. Through the analysis, we can draw the conclusion that the V-straightening has the effect not only on the distribution of residual stress but also on the value of residual stress, the residual value is up to $51.1 \mathrm{MPa}$.

The residual stress of rail bottom after straightening shows in Table 3. It is shown in Table 3, after H-straightening, the maximum value of rail bottom residual stress (in straightening blind area) is $289.6 \mathrm{MPa}$, and the average of rail bottom residual stress is $81.1 \mathrm{MPa}$. After $\mathrm{V}$-straightening, the maximum value of residual stress reduced by 99.0 $\mathrm{MPa}$, and changed to 190.6 MPa. Whereas, after V-straightening, the average of rail bottom residual stress increased by $11.6 \mathrm{MPa}$, and changed to $81.1 \mathrm{MPa}$.

According to the active straightening regulation, the rail bottom residual stress contour after $\mathrm{H}$-straightening and compound straightening shows in Fig. 9. The residual stress of nodes (451 nodes in all) which is in the middle line of rail bottom after the compound straightening shows in Fig. 10. From the Figs 9 and 10 we can find the rail bottom residual stress after H-straightening is mainly tensile stress, but the distribution is not in uniform. The maximum rail bottom residual stress comes out at the distance $800 \mathrm{~mm}$ from rail end, it reached to 289.6 MPa. Rail bottom residual stress after the compound straightening (except the blind area) is tensile stress, it is in uniform under the value of $250 \mathrm{MPa}$, the stress value meets GB standard.

Figures 9 and 10 show that V-straightening can not only decrease the maximum residual stress but also can make rail bottom residual stress more regular.

\section{The design of simulation calculation}

In the actual compound straightening process, the reductions of $2 \#, 4 \#, 6 \#$ and $8 \#$ roller in the $\mathrm{H}$-straightener can be adjusted, the reduction of $11 \#, 13 \#, 15 \#$ and $17 \#$ roller in the V-straightener can also be adjusted. In the 
Table 4

The reduction corresponding to each straightening regulation

\begin{tabular}{cccccccc}
\hline $\begin{array}{c}\text { factor } \\
\text { level }\end{array}$ & $\begin{array}{c}\mathrm{A} \\
\text { 2\# roller }\end{array}$ & $\begin{array}{c}\mathrm{B} \\
\text { 4\# roller }\end{array}$ & $\begin{array}{c}\mathrm{C} \\
\text { 6\# roller }\end{array}$ & $\begin{array}{c}\mathrm{D} \\
\text { 8\# roller }\end{array}$ & $\begin{array}{c}\mathrm{E} \\
\text { 11\# roller }\end{array}$ & $\begin{array}{c}\mathrm{F} \\
\text { 13\# roller }\end{array}$ & $\begin{array}{c}\mathrm{G} \\
\text { 15\# roller }\end{array}$ \\
\hline 1 & 21.2 & 13.2 & 9.9 & 5.5 & 14.0 & 8.0 & 4.5 \\
2 & 20.2 & 12.2 & 8.9 & 4.5 & 13.0 & 7.0 & 3.5 \\
3 & 19.2 & 11.2 & 7.9 & 3.5 & 12.0 & 6.0 & 2.5 \\
4 & 18.2 & 10.2 & 6.9 & 2.5 & 11.0 & 5.0 & 1.5 \\
5 & 17.2 & 9.2 & 5.9 & 1.5 & 10.0 & 4.0 & 0.5 \\
\hline
\end{tabular}

LS-DYNA user input
Time $=4.508$
Contours of $Z$-stress
min=-310.484, at elem\# 182746
max $=350.388$, at elem\# 182002

(a) the rail bottom residual stress after H-straightening
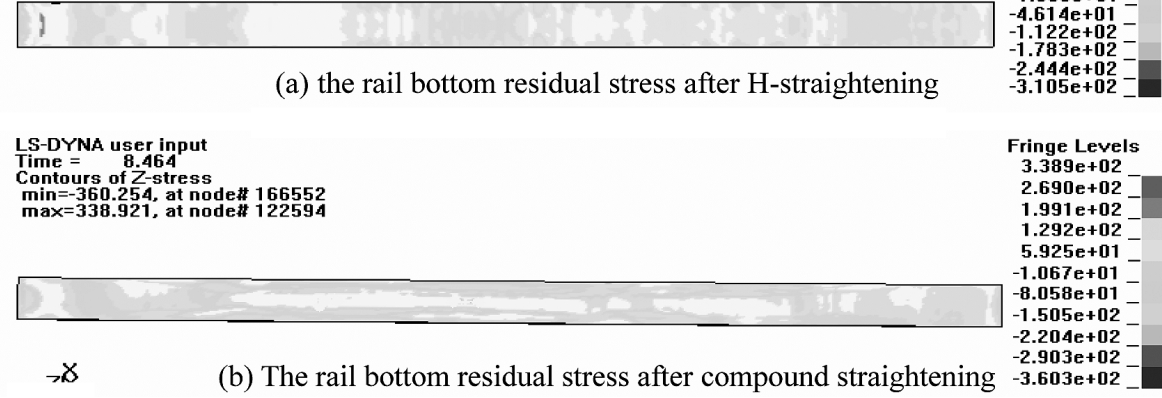

Fig. 9. The residual stress of rail bottom.

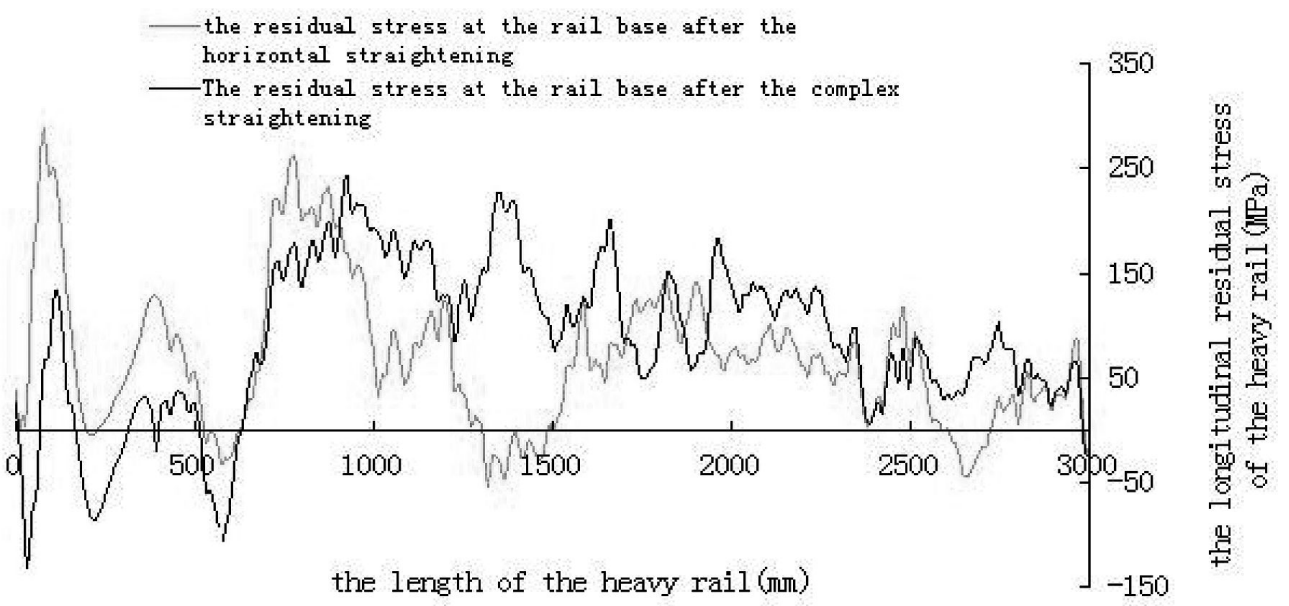

Fig. 10. The mid-nodes residual stress value of rail bottom.

simulation calculation, the adjustable roller is taken as the main factor, and the reduction corresponding to each roller is taken as the level. In the on-site straightening regulation, 17 \# roller in the V-straightener does not roll down, the reduction value is $0 \mathrm{~mm}$, the active reduction value of $2 \#, 4 \#, 6 \#, 8 \#, 11 \#, 13 \#$ and $15 \#$ roller are respectively $19.2 \mathrm{~mm}, 11.2 \mathrm{~mm}, 7.9 \mathrm{~mm}, 3.5 \mathrm{~mm}, 12.0 \mathrm{~mm}, 6.0 \mathrm{~mm}$ and $2.5 \mathrm{~mm}$. Therefore, the reduction of $2 \#, 4 \#, 6 \#, 8 \#, 11 \#, 13 \#$ and 15\# rollers are chosen as the main factors of the simulation calculation, which are totally 7 factors. As to each adjustable roller we set 5 reductions, so each factor consists of five levels. We carried out the orthogonal calculation according to the rules $[11,12]$, it is shown in Table 4 . The seven factors and five levels orthogonal calculation program of rail straightening is listed in Table 5, the calculation is carried out 50 times. According to the orthogonal calculation program in Table 5, the numerical simulation is implemented, and the post-processing was done to the 
Table 5

The orthogonal simulation calculation corresponding to the simulation result

\begin{tabular}{|c|c|c|}
\hline No. & calculation plan & residual stress $(\mathrm{MPa})$ \\
\hline 1 & A1-B1-C1-D1-E1-F1-G1 & 162.7 \\
\hline 2 & A1-B1-C1-D1-E1-F1-G2 & 194.1 \\
\hline 3 & A1-B2-C2-D2-E2-F2-G3 & 236.7 \\
\hline 4 & A1-B2-C2-D2-E2-F2-G4 & 208.6 \\
\hline 5 & A1-B3-C3-D3-E3-F3-G5 & 203.0 \\
\hline 6 & A1-B3-C3-D3-E3-F3-G1 & 256.6 \\
\hline 7 & A1-B4-C4-D4-E4-F4-G2 & 161.3 \\
\hline 8 & A1-B4-C4-D4-E4-F4-G3 & 207.0 \\
\hline 9 & A1-B5-C5-D5-E5-F5-G4 & 153.0 \\
\hline 10 & A1-B5-C5-D5-E5-F5-G5 & 163.1 \\
\hline 11 & A2-B1-C2-D3-E4-F5-G1 & 222.7 \\
\hline 12 & A2-B1-C2-D3-E4-F5-G2 & 260.6 \\
\hline 13 & A2-B2-C3-D4-E5-F1-G3 & 214.3 \\
\hline 14 & A2-B2-C3-D4-E5-F1-G4 & 292.0 \\
\hline 15 & A2-B3-C4-D5-E1-F2-G5 & 282.1 \\
\hline 16 & A2-B3-C4-D5-E1-F2-G1 & 269.2 \\
\hline 17 & A2-B4-C5-D1-E2-F3-G2 & 168.0 \\
\hline 18 & A2-B4-C5-D1-E2-F3-G3 & 187.4 \\
\hline 19 & $\mathrm{~A} 2-\mathrm{B} 5-\mathrm{C} 1-\mathrm{D} 2-\mathrm{E} 3-\mathrm{F} 4-\mathrm{G} 4$ & 228.5 \\
\hline 20 & A2-B5-C1-D2-E3-F4-G5 & 215.4 \\
\hline 21 & A3-B1-C3-D5-E2-F4-G1 & 255.6 \\
\hline 22 & A3-B1-C3-D5-E2-F4-G2 & 227.5 \\
\hline 23 & A3-B2-C4-D1-E3-F5-G3 & 161.4 \\
\hline 24 & A3-B2-C4-D1-E3-F5-G4 & 183.2 \\
\hline 25 & A3-B3-C5-D2-E4-F1-G5 & 161.6 \\
\hline 26 & A3-B3-C5-D2-E4-F1-G1 & 165.8 \\
\hline 27 & A3-B4-C1-D3-E5-F2-G2 & 224.8 \\
\hline 28 & A3-B4-C1-D3-E5-F2-G3 & 184.9 \\
\hline 29 & A3-B5-C2-D4-E1-F3-G4 & 305.0 \\
\hline 30 & A3-B5-C2-D4-E1-F3-G5 & 333.6 \\
\hline 31 & A4-B1-C4-D2-E5-F3-G1 & 189.2 \\
\hline 32 & A4-B1-C4-D2-E5-F3-G2 & 254.0 \\
\hline 33 & A4-B2-C5-D3-E1-F4-G3 & 209.3 \\
\hline 34 & A4-B2-C5-D3-E1-F4-G4 & 245.1 \\
\hline 35 & A4-B3-C1-D4-E2-F5-G5 & 340.8 \\
\hline 36 & A4-B3-C1-D4-E2-F5-G1 & 351.3 \\
\hline 37 & A4-B4-C2-D5-E3-F1-G2 & 223.9 \\
\hline 38 & A4-B4-C2-D5-E3-F1-G3 & 233.5 \\
\hline 39 & A4-B5-C3-D1-E4-F2-G4 & 248.6 \\
\hline 40 & A4-B5-C3-D1-E4-F2-G5 & 198.7 \\
\hline 41 & A5-B1-C5-D4-E3-F2-G1 & 201.1 \\
\hline 42 & A5-B1-C5-D4-E3-F2-G2 & 197.8 \\
\hline 43 & A5-B2-C1-D5-E4-F3-G3 & 248.5 \\
\hline 44 & A5-B2-C1-D5-E4-F3-G4 & 197.8 \\
\hline 45 & A5-B3-C2-D1-E5-F4-G5 & 159.2 \\
\hline 46 & A5-B3-C2-D1-E5-F4-G1 & 209.6 \\
\hline 47 & A5-B4-C3-D2-E1-F5-G2 & 216.5 \\
\hline 48 & A5-B4-C3-D2-E1-F5-G3 & 228.7 \\
\hline 49 & A5-B5-C4-D3-E2-F1-G4 & 251.0 \\
\hline 50 & A5-B5-C4-D3-E2-F1-G5 & 235.6 \\
\hline
\end{tabular}

simulation results. The longitudinal residual stress value of rail was obtained through the compound straightening, the result is shown in Table 5 .

\section{Optimization straightening on residual stress}

Taking consideration of the rail production process, the residual stress of rail is inevitable. As far as the production 
Table 6

The orthogonal analysis diagram of residual stress at rail bottom after compound straightening

\begin{tabular}{cccccccc}
\hline & & \multicolumn{5}{c}{ visual analysis on the maximum residual stress } \\
\cline { 3 - 7 } & 2\# roller & 4\# roller & 6\# roller & 8\# roller & 11\# roller & 13\# roller & 15\# roller \\
\hline$K_{1}$ & 1946.0 & 2165.2 & 2348.8 & 1873.0 & 2446.3 & 2134.5 & 2283.7 \\
$K_{2}$ & 2340.2 & 2196.9 & 2393.3 & 2104.9 & 2462.6 & 2252.6 & 2128.6 \\
$K_{3}$ & 2203.4 & 2399.1 & 2341.6 & 2293.7 & 2104.2 & 2343.1 & 2111.7 \\
$K_{4}$ & 2494.4 & 2036.1 & 2194.0 & 2604.2 & 2072.6 & 2118.4 & 2313.0 \\
$K_{5}$ & 2145.9 & 2332.6 & 1852.2 & 2254.1 & 2044.2 & 2281.4 & 2293.0 \\
$k_{1}$ & 194.6 & 216.5 & 234.9 & 187.3 & 244.6 & 213.4 & 228.4 \\
$k_{2}$ & 234.0 & 219.7 & 239.3 & 210.5 & 246.3 & 225.3 & 212.9 \\
$k_{3}$ & 220.3 & 239.9 & 234.2 & 229.4 & 210.4 & 234.3 & 211.2 \\
$k_{4}$ & 249.4 & 203.6 & 219.4 & 260.4 & 207.3 & 211.8 & 231.3 \\
$k_{5}$ & 214.6 & 233.3 & 185.2 & 225.4 & 204.4 & 228.1 & 229.3 \\
$R$ & 54.8 & 36.3 & 54.1 & 73.1 & 41.8 & 22.5 & 20.1 \\
\hline
\end{tabular}

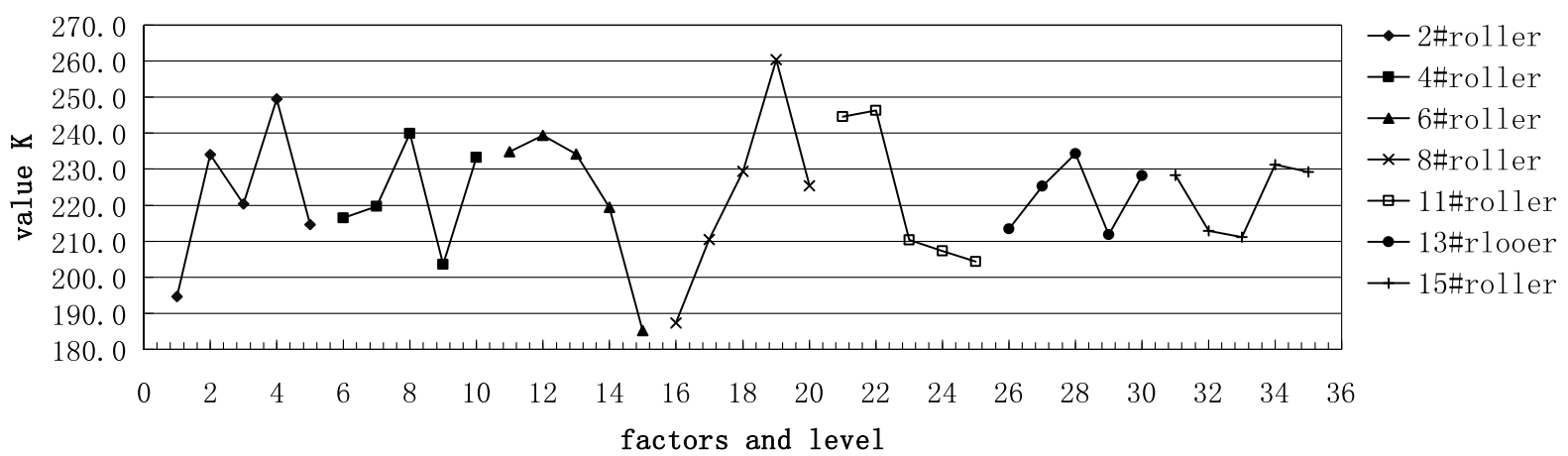

Fig. 11. The relationship of factors, level and value k.

process of the domestic rail manufacturer or the international rail manufacturer is concerned, the residual stress of rail bottom is in tensile state, and then the residual tensile stress in the bottom of rail will come into superposition with the stress which is produced by the running train, thus rail will easily come into failure since the stress value goes beyond the fatigue limit of rail. So the residual stress in the bottom of rail must be warranted. Therefore, this paper mainly considered the optimization plan on residual stress in the rail bottom.

It is found that from Table 6, 2\# roller in the first column appeared 10 times in the one level, and the sum of its 10 corresponding stress values are recorded as $K_{1}$, its average denoted by $k_{1}$. By the same way, other corresponding factors $K_{1}$ and $k_{1}$, and the value $R$ in the last row can be regard as the difference from each column $k_{1}, k_{2}, k_{3}$, $k_{4}, k_{5}$, it is called the factor difference. Table 6 shows the results of residual stress at rail bottom after compound straightening.

From the value $R$ in Table 6 we can know, under the condition that the original curvature radius is $63 \mathrm{~m}, 8 \#$ roller has the most effect on the residual stress in the bottom of rail, and 2\# roller, 6\# roller, 11\# roller, 4\# roller, 13\# roller and $15 \#$ roller effect decrease progressively, that is to say the reductions of $8 \#$ roller, $2 \#$ roller, $6 \#$ roller and $11 \#$ roller are the main factors for decreasing the residual stress in the bottom of rail. In order to facilitate direct analysis, the relation figure of factor and level to value $k$ is made out, it is shown in Fig. 11.

From Fig. 11 we can know, after orthogonal analysis, the optimization plan is A1-B4-C5-D1-E5-F4-G3 which is corresponding to the minimum residual stress of the rail bottom. Through calculating, according to the reduction in the plan above the numerical simulation is carried out, we obtained the maximum residual stress in the bottom of rail, the value is $175.3 \mathrm{MPa}$.

We have carried on the actual measurement to the residual stress of rail bottom, the value is respectively 176.8 $\mathrm{MPa}$, 218.2 MPa, 205.3 MPa, 177.8 MPa, and the average value is $194.525 \mathrm{MPa}$, it is basically conforms to the simulation calculation result. 


\section{Conclusions}

1) The reduction of $8 \#$ straightening roller has the most effect on the residual stress in the bottom of rail, and then the $2 \#$ roller, $6 \#$ roller, 11\# roller, $4 \#$ roller, 13\# roller and 15\# roller effect decrease progressively, that is to say $8 \#$ roller, 2\# roller, $6 \#$ roller and 11\# roller are the main factors for decreasing the residual stress of rail bottom.

2) Under the condition of assuring the minimum residual stress of rail bottom, the plan of A1-B5-C5-D5-E5-F5-G4 is the optimization straightening plan, in the straightening regulation of this plan, the reductions of $2 \#$ roller, 4\# roller, 6\# roller, 8\# roller, 11\# roller, 13\# roller and $15 \#$ roller are respectively $21.2 \mathrm{~mm}, 9.2 \mathrm{~mm}, 5.9 \mathrm{~mm}, 1.5 \mathrm{~mm}$, $10.0 \mathrm{~mm}, 4.0 \mathrm{~mm}$ and $1.5 \mathrm{~mm}$.

\section{Acknowledgement}

This research was supported by National Natural Science Foundation of China (Granted No. 50774043). We also thank the ANSYS LS-DYNA for the computational support of this investigation.

\section{References}

[1] J.O. Igwemezie, S.L. Kenny and N.R. Gore, Residual stresses and catastrophic rail failure, Rail Quality and Maintenance for Modern Railway Operation (1993), 325-336.

[2] R.R. John, Task Force Report Rail Failure Evaluation. U.S. DOT Transportation System Center. Cambridge, May 1984.

[3] R.P. Reiff, Report from FAST-recent test experiences. Transportation Research Record 1174,Transportation Research Board, National Research Council (1998), 81-93.

[4] G. Finstermann, F.D. Fischer, G. Shan and G. Schleinzer, Residual stresses in rails due to roll straightening, Steel Research 69(7) (1998), 272-278.

[5] S.L. Srimani, D.S. Gupta and J. Basu, A finite element approach for residual stress determination in roller-straightened rail, in: Proceedings of the second international conference on theoretical, applied, computational and experimental mechanics, paper053.p.10.

[6] S.L. Srimani and J. Basu, An investigation for control of residual stress in roller-straightened rails, J Strain Analysis 38 (2003), $261-268$.

[7] D. Ding, Study on the Numerical Simulation of H-straightening of rail[Master thesis], Liaoning: Liaoning University of Science and Technology, March 2007.

[8] Z. Wu, Study on the Residual Stress and the Straightness of Heavy Rail Tracks after Straightening [Master thesis], Beijing: University of Science and Technology of Beijing, February 2005.

[9] W. Yang, Study on the Three-Dimentional Numerical Simulation and the Residual stress of High Speed Rail after Compound Straightening [Master thesis]. Neimenggu:University of Science and Technology of Neimenggu, June 2006.

[10] G. Schleinzer and F.D. Fischer, Residual Stress Formation during the Roller Straightening of Railway, Int J Mech Sci 43 (2001), $2281-2295$.

[11] Y. Xin, ANOVA and Experimental Design. Beijing: China Financial and Economic Publishing House, 2002.

[12] Z. Liu, R. Huang and A. Tian, Experimental Design and Data Process. Beijing: Chemical Industry Press, 2005.

[13] W.H. Hodgson, Residual stresses in rail, Rail Quality and Maintenance for Modern Railway Operation (1993), 61-73.

[14] P.M. Besuner, Fracture mechanic analysis of rails with shell initiated transverse cracks, Rail Steels-Developments, Processing, and Use, ASTM STP 644 (1978) (2001), 303-329.

[15] Dangyong SHI,Yuchun LI etc. Explicit dynamics analysis based on ANSYS/LS-DYNA 8.1.Beijing:QingHua university publishing company, 2005.

[16] C. Betegon Biempica, J.J. del Coz Diaz and P.J. Garcia Nieto, Nonlinear analysis of residual stresses in a rail manufacturing process by FEM, Applied Mathematical Modeling, 0307-904X 33(1) (2009), 34-53. 

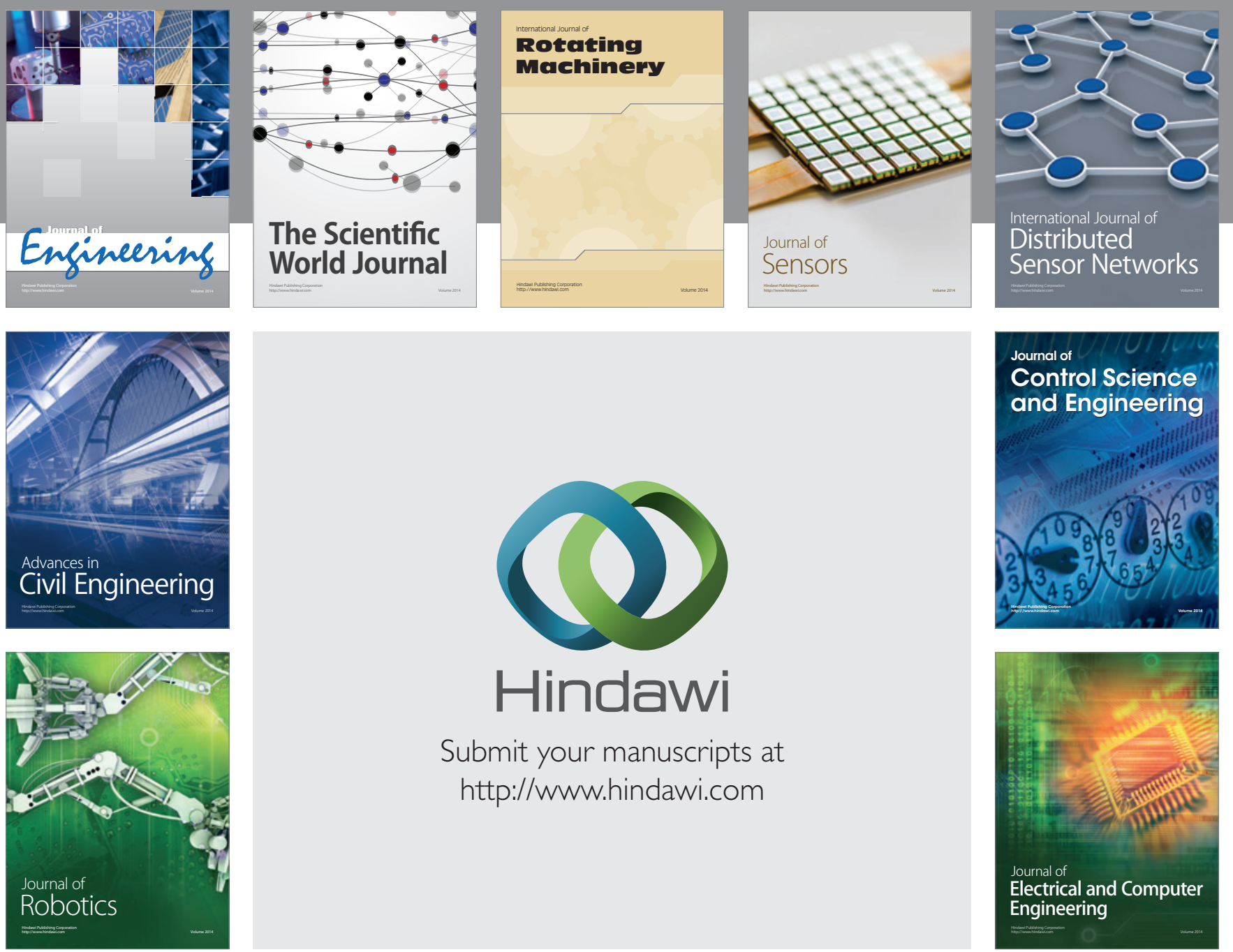

Submit your manuscripts at

http://www.hindawi.com
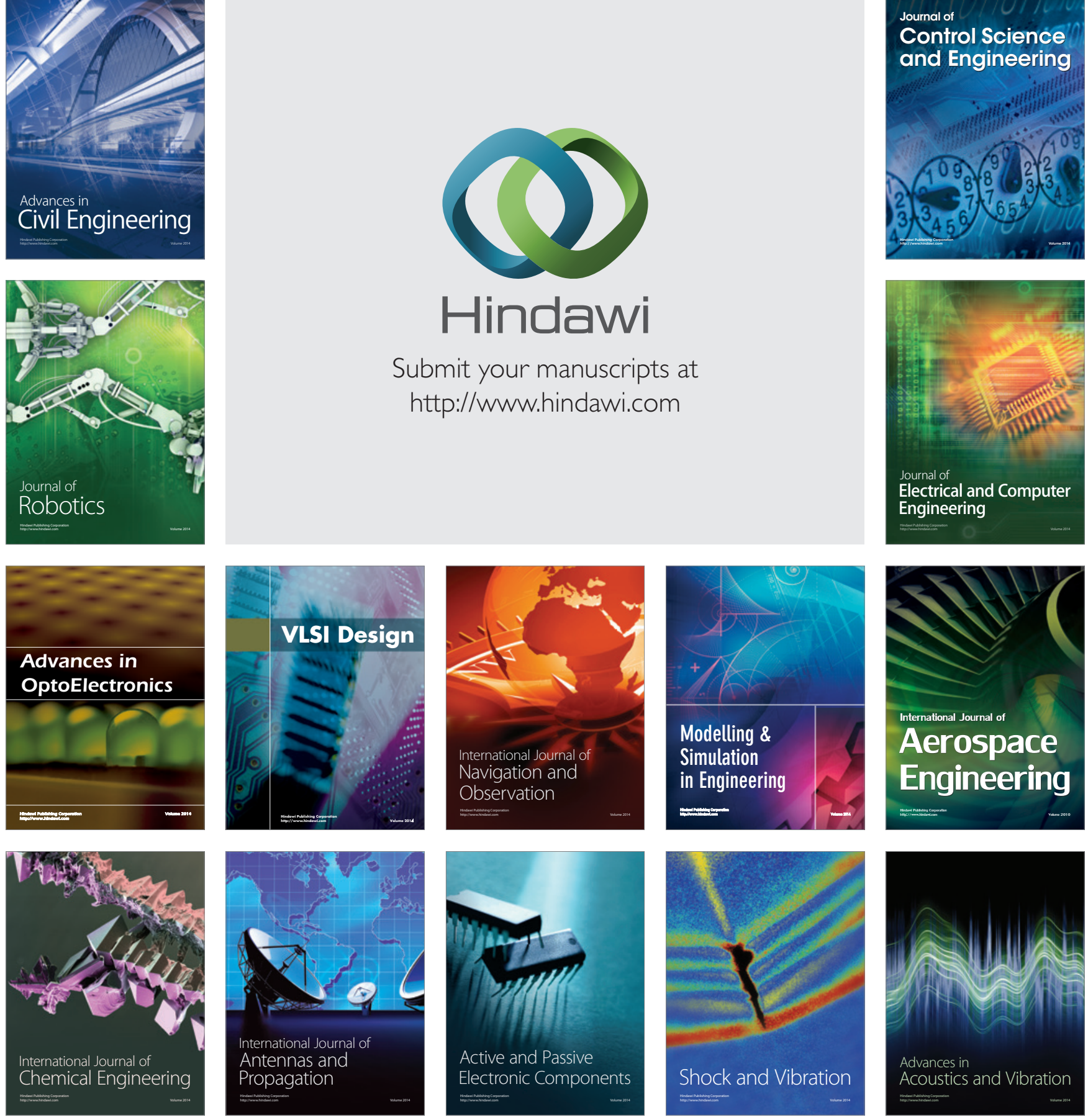